\section{Hemorrhagic gastritis at the excluded stomach after Roux-en-Y gastric bypass}

Anemia frequently occurs in patients after RouX-en-Y gastric bypass. The causes are usually related to surgery, anastomotic site lesions, or malabsorption of nutrients caused by altered anatomy and physiology [1]. A 57-year-old man underwent an uncomplicated laparoscopic Roux-en-Y gastric bypass for morbid obesity and experienced melena and anemia 10 years after surgery. His medical history included hypertension and insulin-dependent diabetes mellitus that disappeared after surgery. Laboratory findings revealed a hemoglobin level of $5.9 \mathrm{~g} / \mathrm{dL}$ and iron deficiency (iron, $47 \mu \mathrm{g} / \mathrm{dL}$; ferritin $11 \mathrm{ng} / \mathrm{mL}$; iron saturation, 8.6\%). His medications included vitamin B12 and omeprazole (20 mg/day). Endoscopy, colonoscopy, and abdominal computed tomography showed no abnormalities apart from anatomical changes related to surgery.

Double-balloon enteroscopy showed the pylorus and hemorrhagic erosive pangastritis at the excluded stomach ( $\bullet$ Fig. 1 and $\odot$ Fig. 2, Video 1). Biopsy specimens were negative for Helicobacter pylori and demonstrated chronic active gastritis, regenerative activity, and foveolar hyperplasia. The omeprazole dosage was increased to $40 \mathrm{mg} / \mathrm{day}$. The patient progressed without melena, and with a continuing increase in the hemoglobin level. After 3 months of treatment, double-balloon enteroscopy revealed atrophic pangastritis, but no bleeding focus. Laboratory tests exhibited a normal iron profile with a hemoglobin level of $15.5 \mathrm{~g} / \mathrm{dL}$, iron $155 \mu \mathrm{g} / \mathrm{dL}$, ferritin $44.7 \mathrm{ng} / \mathrm{mL}$, and iron saturation, $29.5 \%$.

\section{Video 1}

Double-balloon enteroscopy showing hemorrhagic erosive pangastritis at the excluded stomach.
This case shows the importance of double-balloon enteroscopy for examining the excluded stomach in patients with Roux-en-Y gastric bypass. In addition, double-balloon enteroscopy has proven useful for the evaluation and therapy of obscure gastrointestinal bleeding in patients with a surgically altered upper gastrointestinal anatomy [2].

Endoscopy_UCTN_Code_CCL_1AB_2AD_3AC

Competing interests: None

\section{Adriana Vaz Safatle-Ribeiro ${ }^{1}$, Emanuele Lima Villela ${ }^{1}$, Eduardo Guimarães Hourneaux de Moura ${ }^{1}$, Paulo Sakai ${ }^{1}$, Klaus Mönkemüller ${ }^{2}$}

${ }^{1}$ Endoscopy Unit of the Hospital das Clínicas, Department of Gastroenterology, University of São Paulo School of Medicine, São Paulo, Brazil

${ }^{2}$ Hirschowitz Endoscopic Center of Excellence, Division of Gastroenterology and Hepatology, University of Alabama at Birmingham, Birmingham, USA

\section{References}

1 Obinwanne KM, Fredrickson KA, Mathiason $M A$ et al. Incidence, treatment, and outcomes of iron deficiency after laparoscopic Roux-en-Y gastric bypass: a 10-year analysis. J Am Coll Surg 2014; 218: 246-252

2 Safatle-Ribeiro AV, Kuga R, Iriya K et al. What to expect in the excluded stomach mucosa after vertical banded Roux-en-Y gastric bypass for morbid obesity. J Gastrointest Surg 2007; 11: 133-137

\section{Bibliography}

Dol http://dx.doi.org/

10.1055/s-0034-1390778

Endoscopy 2014; 46: E630

(c) Georg Thieme Verlag KG

Stuttgart · New York

ISSN 0013-726X

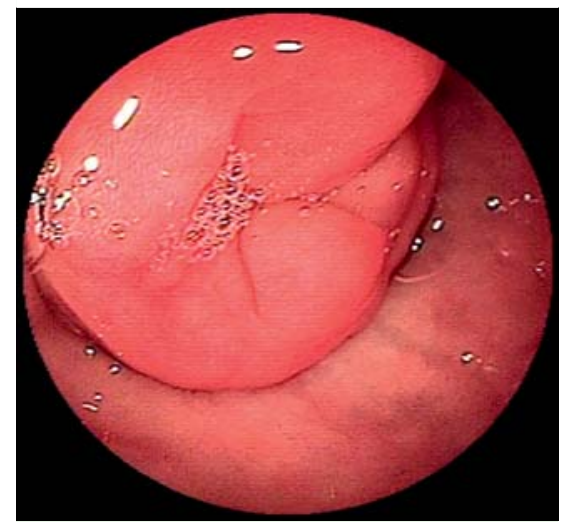

Fig. 1 Endoscopic view of the pylorus from the duodenum in a 57-year-old man who had undergone an uncomplicated laparoscopic Roux-en-Y gastric bypass for morbid obesity 10 years earlier and who was experiencing melena and anemia.

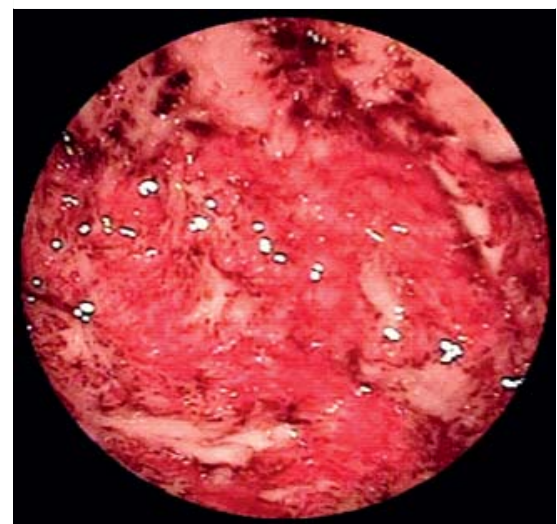

Fig.2 Endoscopic image of hemorrhagic erosive gastritis at the excluded stomach 10 years after Roux-en-Y gastric bypass for morbid obesity.

\section{Corresponding author}

\section{Adriana Vaz Safatle-Ribeiro, MD, PhD}

University of São Paulo School of Medicine Department of Gastroenterology Endoscopy Unit of the Hospital das Clínicas Av. Dr. Enéas de Carvalho Aguiar, 255 - Cerqueira César

São Paulo - SP

Brazil

Fax: +55-11-32849885

adrisafatleribeiro@terra.com.br 